(114)

\title{
Determination of Grey Water Footprint of Rice Cultivation in the Right Bank of Nilwala Downstream
}

\author{
Rathnappriya R H.K. ${ }^{1 *}$, Navaratne C.M. ${ }^{1}$ and Rathnayake U. ${ }^{2}$ \\ ${ }^{I}$ Department of Agricultural Engineering, Faculty of Agriculture, University of Ruhuna, Sri Lanka \\ ${ }^{2}$ Agricultural Research Station, Labuduwa, Sri Lanka \\ *himashakithminir@gmail.com
}

\begin{abstract}
Excess nutrients released through leaching and/or runoff from agricultural lands into natural water bodies has caused water pollution all over the world. Water pollution by means of discharging chemical substances from paddy fields to water bodies has become a critical problem in Sri Lanka. The grey water footprint is considered as a rough estimate of water pollution associated with a particular activity. The grey water footprint associated with the paddy cultivation in the right bank of "Nilwala" downstream was calculated based on two levels of fertilizer applications; level 1: fertilization according to the recommendations of the Department of Agriculture, Sri Lanka and level 2: fertilization based on farmer's preferences. Sampling was performed once a day for a week after each fertilization. Nitrate concentration of water samples was analyzed through Ultraviolet Spectrometric Screening method while $\mathrm{pH}$ and electrical conductivity were measured using $\mathrm{pH}$ meter and conductivity meter, respectively. Daily rainfall over the study area was recorded throughout the study period. The grey water footprint calculated based on the nitrate discharge for fertilization level 1 and level 2 were $0.93 \mathrm{~m}^{3} / \mathrm{ha}$ and $2.26 \mathrm{~m}^{3} /$ ha respectively. As it is analyzed by the one-sample t-tests, the nitrate concentrations, $\mathrm{pH}$ and electrical conductivity of paddy water are significantly lower than that of proposed ambient water quality standards for Sri Lanka. As revealed by two-sample t-tests, nitrate concentrations, $\mathrm{pH}$ and electrical conductivity of water samples were significantly different from each other with respect to the both levels of fertilization. However, the nitrate concentrations and electrical conductivity values of water samples related to both levels of fertilization and $\mathrm{pH}$ values related to fertilization level 1, were significantly higher than that of raw water in "Nilwala" river which is used for irrigation, while $\mathrm{pH}$ values related to fertilization level 2 were significantly lower than the same.
\end{abstract}

Keywords: Grey water footprint, Paddy cultivation, Nitrate, $\mathrm{pH}$, Electrical conductivity

Proceedings of the International Forestry and Environment Symposium 2016, Department of Forestry and Environmental Science, University of Sri Jayewardenepura, Sri Lanka. 